\title{
Computer Anxiety in E-Learning: The Effect of Computer Self-Efficacy
}

\author{
Raafat George Saadé and Dennis Kira \\ Concordia University, John Molson School of Business, \\ Montréal, Qc, Canada
}

\section{rsaade@jmsb.concordia.ca; dkira@jmsb.concordia.ca \\ Executive Summary}

It has been reported that as many as fifty percent of adults, including first-year University students, have some sort of computer-related phobia. This report demonstrates that the use of computers still has some unpleasant side effects despite the Internet boom in the past decade. Past research shows that computer anxiety influences how users perceive ease of use of an information system. However, few have investigated the role of computer self-efficacy in mediating computer anxieties on perceived ease of use. Therefore, in this study we base our contribution on the variables of computer self-efficacy and computer anxieties. These two variables are believed to impact an individual's use of computers and performance for computer-based tasks. Anxiety has been argued to impact computer-based learning by affecting levels of self-efficacy anchored in social learning and outcome expectation theories. Self-efficacy is determined by levels of anxiety such that reduced anxiety and increased experience improves performance indirectly by increasing levels of self-efficacy. In this study, we investigate the influence of computer anxiety on perceived ease of use and the mediating effect of computer self-efficacy on this relationship, within an e-learning context. A survey methodology approach was used in this study using 18 items for 3 constructs (perceived ease of use, anxiety, and self-efficacy). Survey data from 645 university students were analyzed. The psychometric properties of the items and constructs were validated followed by the assessment of mediation of computer self efficacy. Results from the use of a learning management system indicate that computer self-efficacy plays a significant role in mediating the impact of anxiety on perceived ease of use. This role is observed by computer selfefficacy (1) reducing the strength and significance of the impact of anxiety on perceived ease of use and (2) having a strong and significant relationship with computer anxiety. The findings demonstrate the importance of self-efficacy as a mediator between computer anxiety and perceived ease of use of a learning management system (LMS). With the continuous development of richer and more integrated interfaces, anxieties about learning to use the new interface and executing tasks effectively becomes of primary importance. Limitations and suggestions for future research are elaborated.

Material published as part of this publication, either on-line or in print, is copyrighted by the Informing Science Institute. Permission to make digital or paper copy of part or all of these works for personal or classroom use is granted without fee provided that the copies are not made or distributed for profit or commercial advantage AND that copies 1) bear this notice in full and 2) give the full citation on the first page. It is permissible to abstract these works so long as credit is given. To copy in all other cases or to republish or to post on a server or to redistribute to lists requires specific permission and payment of a fee. Contact Publisher@InformingScience.org to request redistribution permission.
Keywords: Online learning; Anxiety; Computer Self-Efficacy; Perceived ease of use

\section{Introduction}

E-learning as a new paradigm for higher education has been steadily gaining support for the past ten years. Stakeholders at different levels, such as researchers, practitioners, and institutions, under- 
stand the value of e-learning. This understanding has even been strengthened due to our difficult and trying present times and economical instability. In fact, e-learning today has become widely recognized as an environment to challenge face-to-face teaching altogether (Saadé, 2007). Expected productivity gains, however, and benefits to students and academic institutions promised by the e-learning approach cannot be realized unless they are effectively used (Ivari \& Ervasti, 1994; Saadé \& Kira, 2007). Additionally, acceptance, adoption, and satisfaction of the e-learning experience have been identified as a critical issue in its usage (Deci \& Ryan, 1985).

Many theoretical frameworks have been used to measure technology usage satisfaction, acceptance, and adoption; however relatively few have been used in the e-learning context. The Technology Acceptance Model (TAM), for example, has been extensively used to understand technology adoption. The goal of TAM is "to provide an explanation of the determinants of computer acceptance that is in general, capable of explaining user behavior across a broad range of end-user computing technologies and user populations, while at the same time being both parsimonious and theoretically justified" (Davis, 1986, 1989; Davis, Bagozzi, \& Warshaw, 1989).

In the context of e-learning, a student's 'likelihood of use' of a specific system (in this case the learning management system (LMS)) is jointly determined by their attitude toward using the system and perceived ease of use (PEU). This implies that the easier the system is to use, the greater will be the user's perceived self efficacy regarding their capacity to use the system comfortably. External variables used with TAM include individual differences, situational constraints, organizational characteristics, and system characteristics. TAM emphasizes the importance of how external variables can affect the students' internal decision process when it comes to using a learning management system within their educational institution. External variables affect perceived usefulness (PU) directly or indirectly through PEU since it influences the student's near-term perception of usefulness and, to the lesser extent, long-term (Compeau, Higgins, \& Huff, 1999). Direct experience with an LMS, its characteristics (P. Y. K. Chau, 1996), and student prior experience and feeling about it determine the student's perception of ease of use of it (Lucas \& Spitler, 1999). According to previous studies, efficacy and computer anxiety were all determinants of PEU (Gefen, Karahanna, \& Straub, 2003a, 2003b; Gefen \& Straub, 1997; Pedersen \& Nysveen, 2003).

Learning management systems are designed to facilitate the learning process, and therefore their PEU is a necessity especially with first time users. Much effort has been devoted to creating user friendly interfaces, in recognition of the importance of PEU (Venkatesh \& Morris, 2000). With web-based LMSs several studies have pointed out that factors relating to 'ease' with which information can be found on a web site and the 'ease' with which information can be understood affect web site's perceived ease of use (Lederer, Maupin, Sena, \& Zhuang, 2000).

Motivated by previous anxiety-beliefs research work, we hope in this study to provide additional understanding of what mediating role computer self-efficacy (CSE) plays in the anxiety (ANX) and perceived ease of use (PEU) relationship. Our study involves 649 students made up of three groups that used an LMS over a period of one year (3 semesters). Prior research in information systems has investigated the constructs mentioned herein to understand individual reactions to computer systems (Agarwal \& Karahanna, 2000; Howard \& Smith, 1986; Venkatesh \& Davis, 2000); however, few have used an LMS as the target technology and have directly compared and contrasted the mediating effect of CSE to understand its impact on the ANX-PEU relationship.

\section{Development of Research Hypotheses}

The present research deals with computer anxiety, computer self-efficacy, and perceived ease of use of a learning management system. Anxiety is a feeling that primarily belongs in the psychology domain. Self-efficacy is anchored in the expectation theory, and PEU, which is a construct in 
the technology acceptance model, was given birth from the theory of reasoned action. The present research work looks into the relationship between anxiety and PEU and the mediating role of computer self-efficacy in that relationship. As such, in this section we will review the theory behind anxiety, anxiety and PEU, and computer self-efficacy in order to construct our hypotheses.

\section{Anxiety}

Use of technology sometimes has unpleasant side effects, which may include strong, negative emotional states that arise not only during interaction but even before, when the idea of having to interact with the computer begins. Frustration, confusion, anger, anxiety, and similar emotional states can affect not only the interaction itself, but also productivity, learning, social relationships, and overall well-being. There are a number of related definitions explaining what anxiety is:

- Leso and Peck (1992) define computer anxiety

"as a feeling of being fearful or apprehensive

when using or considering the use of a computer."

Evidently, factors such as the context in which an individual was first introduced to the computer (Brosnan, 1998a, 1998b; Rosen \& Weil, 1995), past failure and successes with hardware or software, and the current tasks being attempted, including the use of a new computer applications (Saadé \& Otrakji, 2007), are all determinants of the state and type of anxiety the individual is experiencing. These researchers have attempted to predict those who will experience computer anxiety by identifying factors that correlate with its occurrence. Frequently, such factors as selfefficacy and attitudes towards computer usage are posited as influencing the computer anxiety (Ayersman \& Reed, 1995; Igbaria \& Chakrabarti, 1990; Reed, Ayersman, \& Liu, 1996). There are three types of anxieties: trait, state, and concept-specific.

Trait anxiety is defined as a general pervasive anxiety that is experienced by a person over the entire range of life experience. People who exhibit trait anxiety are chronically anxious and constantly under tension regardless of their situation. This anxiety is frequently used as a construct for personality, learning theory, and psychopathology. Trait anxiety defines a personality characteristic and may be inherited (Howard \& Smith, 1986).

State anxiety is experienced as anxiety that fluctuates over time and arises to a responsive situation. State anxiety is related to a person's learning background. A person may have experienced some anxiety in a situation and that anxiety is transferred to a similar situation.

Concept-specific anxiety is a transitory-neurotic type of anxiety. Concept-specific anxiety is the range between the trait and state anxieties. It is an anxiety that is associated with a specific situation. Therefore, computer anxiety is a concept-specific anxiety because it is a feeling that is associated with a person's interaction with computers (Oetting, 1983).

- In fact, Howard and Smith (1986) define computer anxiety

"as the tendency of a person to experience a level of uneasiness over his or her impending use of a computer."

In information systems study, anxiety has been viewed as a personality variable that influences system use (Agarwal \& Karahanna, 2000). A number of IS studies are consistent with the view that the relationship between anxiety and behavior is mediated by the personal beliefs (Schlenker \& Leary, 1982) and anxiety is incorporated as an antecedent to the beliefs of usefulness and ease of use (e.g., Igbaria, 1993; Venkatesh \& Davis, 2000). It is interesting to note that classical view of anxiety is that it mediates the relationship between beliefs and behavior (Spielberger, 1972). Thus, anxiety can be viewed as a result of the beliefs an individual has, rather than as an antecedent to them. For example, an individual who has a belief that s/he will be embarrassed by deliv- 
ering a speech has speech anxiety (commonly called stage fright); as a result of the anxiety, s/he refuses to give speeches. The belief leads to the fear (i.e., anxiety), which leads to the behavior (i.e., avoidance). Following the same line of reasoning, one could presume that a student (in some cases) who has a belief that $\mathrm{s} / \mathrm{he}$ will experience technological problems while doing an online test has computer anxiety; as a result of the anxiety, s/he will be paranoid about computer problems while doing the online test. The belief leads to fear, which leads to the behavior of paranoia, thereby causing the student to be less focused on doing the test (leading to reduced performance.)

- Igbaria and Parasuraman (1989) apply these theories and define computer anxiety

"as the tendency of individuals to be uneasy, apprehensive, or fearful about current or future use of computers".

A number of studies have provided evidence supporting a direct relationship between computer anxiety and computer use (Brosnan, 1999; S. L. Chau, Chen, \& Wong, 1999; Howard \& Mendelow, 1991; Igbaria, Parasuraman, \& Baroudi, 1996). The computer anxiety research clearly shows that a highly computer anxious individual will be at a significant disadvantage compared to his/her peers. One example of such an environment is an e-learning offered by many higher learning institutions.

\section{Anxiety \& Perceived Ease of Use}

Prior research has shown that past experience is a determinant of behavior (Ajzen \& Fishbein, 1980). In general, TAM identifies the relationships between PEU, PU, attitude (ATT), and behavioral intentions (BI) towards a target system (Davis et al., 1989). In the context of the present elearning study, perceived ease of use (PEU) refers to the degree to which the student expects the LMS to be free from cognitive effort (Davis et al., 1989). Enhanced course performance implies that the student can obtain a better grade by using the LMS without any usage difficulties (Igbara \& Tan, 1997, Saadé \& Bahli, 2005). Students' perception of enhanced performance affects attitudes. In other words, students that perceive the system to be easy to use, develop better attitudes towards the LMS as reported by previous studies (Adams, Nelson, \& Todd, 1992; Pedersen \& Nysveen, 2003; Saadé \& Kira, 2007). Specifically we make the following hypothesis (H1) related to ANX and PEU, shown in Figure 1.

H1: Computer anxiety will have an effect on students' perceived ease of use of the LMS.

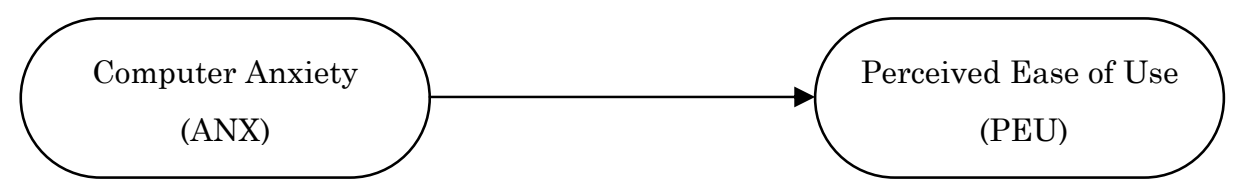

Figure 1. Effect of Computer Anxiety on PEU

\section{Self-efficacy}

In his seminal articles, Bandura (1977, 1978, 1982, 1986a, 1986b, 1988) identifies self-efficacy as a construct often used to explain one's ability to judge how well he/she can execute a task to achieve a desired goal. Self-efficacy was initially defined as an individual's belief about his/her ability to successfully execute a behavior required to produce a desired outcome. This was further refined in his $1986 \mathrm{~b}$ article where Bandura highlighted the importance of distinguishing between component skills and the ability to perform actions. To this end, further clarification was 
offered by other researchers emphasizing that the self-efficacy is a person's belief in his/her capability to perform specific tasks and it consists of three dimensions: Magnitude, Strength and Generality:

(A) Magnitude - the level of task difficulty an individual believes that he or she can attain,

(B) Strength - the confidence one has in attaining a particular level of difficulty and

(C) Generality - the degree to which the expectation is generalized across situations.

Researchers have shown that it is important to capture both the magnitude and strength dimensions when measuring self-efficacy. Therefore, the concept of self-efficacy is context specific (or the valuing of self through specifically defined situations) and highlights the importance of distinguishing between component skills and the ability to perform actions. Further studies by Bandura discussed the psychological construct of self-efficacy as a concept that referred "to beliefs in one's capabilities to mobilize the motivation, cognitive resources and courses of action needed to meet situational demands" (Bandura \& Cervone, 1986). From his observation of the results from various experiments, Bandura (1982) concluded that "perceived efficacy is often a better predictor of behavior in generalization tests than is past performance. ... Behavior is raw data that must be cognitively appraised for its efficacy value."

\section{Computer Anxiety and Self-efficacy}

It would be particularly important to establish measures of psychological constructs that impact an individual's use of computers or performance for computer-based tasks. Two such variables are computer self-efficacy and computer anxiety. Anxiety has been argued to affect computerbased learning by affecting levels of self-efficacy. Self-efficacy emanates from social learning and outcome expectation theories, as indicated above. Self-efficacy is determined by levels of anxiety in addition to enactive and vicarious experience. Enactive experience refers to actual experience. Vicarious information and verbal persuasion increase levels of self-efficacy. Reduced anxiety and increased experience only facilitate performance upon tasks indirectly by increasing levels of self-efficacy which, in turn, leads to improved performance (Bandura, 1977, 1986a; Schunk, 2000). Previous research has confirmed that high levels of computer anxiety reduce levels of self-efficacy which in turn lowers computer-based performance attainment. Similarly, experience with computers also only improves subsequent computer performance if the experience leads to increased levels of self-efficacy (McInerney, McInerney, \& Sinclair, 1994).

There is evidence to suggest, therefore, that the lack of a relationship between anxiety and computer performance is due to self-efficacy moderating this relationship (Saadé \& Kira, 2007). That is, anxiety predicts levels of self-efficacy, which in turn predict performance. The relationship between computer anxiety, CSE, and PEU is made particularly important by the increase in computer-based learning within every level of the educational system. The impact of computer anxiety upon learning is now of major concern within the education system (Brosnan, 1999; Rosen \& Weil, 1995). In this study, computer anxiety, computer self-efficacy, and perceived ease of use will be investigated. The aim is therefore to investigate the relationship between computer anxiety and computer-related perceived ease of use. Based on the above, we hypothesize the following (Figure 2): 
H2: Computer self-efficacy significantly mediates the effect of computer anxiety on perceived ease of use of an LMS.

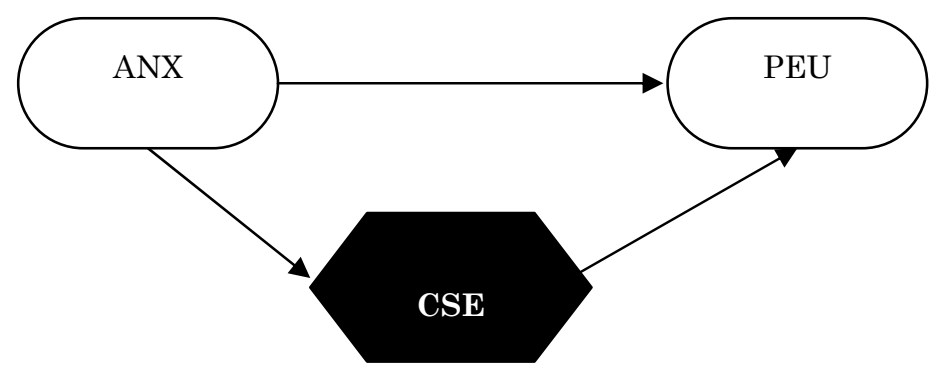

Figure 2. Mediation of computer self-efficacy on ANX-PEU relationship.

\section{The Study}

The study was conducted in an undergraduate online course setting spanning one year, using an LMS (developed in-house) as the target system. Throughout the year, students in an introductory management information systems (MIS) and fundamentals of information technology (FIT) courses at a major university in Canada used the LMS to access course material and to interact with system content, classmates, and professor. The LMS is web based and can be accessed using any web browser. The LMS monitored the students' activities by storing the date and time of login and access to the different components of the system.

The LMS is made up of three components: (1) the front end interacts with the user and provides access to the different learning, assessment and support tools, (2) the middle layer stores and controls the learning process and interaction session, and (3) the back end includes the database. As an example, one of the learning tools used in the LMS is called EISEL (Saadé, 2003). The design of EISEL includes a limited number of questions for each chapter. For example, chapter 1 includes 38 questions while chapter 2 may include 112 questions. Students are presented with a set of five questions at a time. After the five questions are answered, the student can click on 'evaluate' and the system will show the correct/wrong answer with a green/red button on the side of each question. The student can then click on 'next' to request another set of questions randomly selected from the pool of questions. This design allows the repetition of the questions, combined with immediate feedback requiring the use of short-term memory, recognition, and recollection skills. A second attempt to answer a question reinforces the students' understanding of the question and of the concept at hand regardless of the outcome of the question the first time it was answered. Students are asked to do a minimum of 20 questions but encouraged to do as many as they feel necessary. Students are asked to develop their own strategies for use of this tool. They are allowed to practice in groups and to refer to any resources and materials. The objective is more to have them engaged in the processing of domain content rather than assessment.

At the end of the semester, a survey instrument was administered. Six hundred and forty nine students participated in this study. Items (shown in Table 1) used to measure the constructs that were adopted from prior research work are presented. Some wording of the items was changed to account for the context of using the LMS. All items were measured using a five-point Likert-type scale with anchors from "Strongly disagree" to "Strongly agree". For self-efficacy, the following text was given to the students:

Some of you may have used online learning tools as part of the course grading scheme. The 'learning tools' you have used is the first attempt to prototype just one part of a larger more sophisticated 'learning management system'. The 
learning tools are intended to enhance your learning experience. The questions below ask you to indicate whether you could use this 'learning tools' under a variety of conditions. For each of the condition, please indicate whether you think you would be able to complete the work using the 'learning tools'. Circle either "Yes" or "No". Then, for each condition that you answered "Yes", please rate your confidence about your first judgment, by writing in a number from 1 to 10 , where 1 indicates "not at all confident" and 10 indicates "totally confident". You may enter any number in this range.

\begin{tabular}{|c|c|c|}
\hline \multicolumn{3}{|c|}{ Table 1: Measures of study constructs. } \\
\hline Construct & Item & Measure \\
\hline \multicolumn{3}{|c|}{ Perceived Ease of Use (PEU) } \\
\hline & PEU1 & $\begin{array}{l}\text { I think that learning to navigate the on-line course components } \\
\text { will be easy for me. }\end{array}$ \\
\hline & PEU2 & $\begin{array}{l}\text { I think that I will find it easy to get the on-line course compo- } \\
\text { nents to do what I want them to do. }\end{array}$ \\
\hline & PEU3 & $\begin{array}{l}\text { I think that it would be easy for me to become skillful at using } \\
\text { the on-line course components. }\end{array}$ \\
\hline & PEU4 & I think that I will find the on-line course easy to use. \\
\hline \multicolumn{3}{|c|}{ Anxiety (ANX) } \\
\hline & ANX1 & I feel apprehensive about using computers. \\
\hline & ANX2 & $\begin{array}{l}\text { It scares me to think that I could cause the computer to destroy a } \\
\text { large amount of information by hitting the wrong key. }\end{array}$ \\
\hline & ANX3 & $\begin{array}{l}\text { I hesitate to use a computer for fear of making mistakes I cannot } \\
\text { correct. }\end{array}$ \\
\hline & ANX4 & Computers are somewhat intimidating to me. \\
\hline \multicolumn{3}{|c|}{ Computer Self-Efficacy (CSE) } \\
\hline \multirow{10}{*}{$\begin{array}{l}\text { I could complete the re- } \\
\text { quired tasks using the } \\
\text { learning tools: }\end{array}$} & CSE1 & $\ldots$ if there was no one around to tell me what to do as I go. \\
\hline & CSE2 & ... if I had never used a 'learning tool' like it before. \\
\hline & CSE3 & ... if I had only the 'learning tool' manuals for reference. \\
\hline & CSE4 & ... if I had seen someone else using it before trying it myself. \\
\hline & CSE5 & ... if I could call someone for help if I got stuck. \\
\hline & CSE6 & ... if someone else had helped me get started. \\
\hline & CSE7 & $\begin{array}{l}\text {... if I had a lot of time to complete the task for which the 'learn- } \\
\text { ing tool' was provided. }\end{array}$ \\
\hline & CSE8 & ... if I had just the built-in help facility for assistance. \\
\hline & CSE9 & ... if someone showed me how to do it first. \\
\hline & CSE10 & $\begin{array}{l}\ldots \text { if I had used similar 'learning tool' like this one before to do } \\
\text { the task. }\end{array}$ \\
\hline
\end{tabular}

All our experiences in relation to students using the LMS pointed towards the existence of anxiety that varied in type and in level across the group. Motivated to gain insight into the students' perceptions of the LMS and document those experiences, we decided to study anxiety as it relates to computer self-efficacy and perceptions. 


\section{Results, Analysis, and Findings}

\section{Assessment of Measurement}

The 645 usable questionnaires were examined for missing data ( 9 missing data were found); a mean substitution was used to generate replacement values for all the missing data. The assessment of the measurement model implies that internal consistency and discriminant validity should be examined as a test of reliability. Reliabilities of individual items were first assessed by examining the scale internal-consistency, Cronbach alpha, which should be higher than 0.5 (Lohmoller, 1989) to indicate that significant variance was shared between each item and the construct. The Cronbach's alpha coefficients summarized in Table 2 are above 0.7 for all three constructs.

\begin{tabular}{|lccc|}
\hline \multicolumn{4}{|c|}{ Table 2: Reliability Assessment } \\
\hline & Cronbach alpha, $\alpha$ & Mean & SD \\
\hline Perceived Ease of Use (PEU) & 0.890 & 3.495 & 0.977 \\
Computer Self-Efficacy (CSE) & 0.929 & 5.291 & 6.747 \\
Anxiety (ANX) & 0.779 & 2.650 & 1.145 \\
\hline
\end{tabular}

For discriminant validity, items should load higher on their own construct than on the others in the model (Table 3 ). These loadings should be higher than 0.7 , following the criterion indicated by Pedersen and Nysveen (2003), to indicate that significant variance was shared between each item and the construct. It is expected that the loadings of all items within a construct should be high on that construct, indicating high convergent validity, and low on the others. The factors, underlying variables that reflect combinations of observable variables, were extracted using the principal components method (varimax rotation), which is an optimum approach to condensation prior to rotation.

\begin{tabular}{|c|c|c|c|}
\hline \multicolumn{4}{|c|}{ Table 3: Factor analysis } \\
\hline & Factor 1 & Factor 2 & Factor 3 \\
\hline PEU1 & 0.119 & 0.790 & -0.195 \\
\hline PEU2 & 0.066 & 0.786 & -0.082 \\
\hline PEU3 & 0.126 & 0.795 & -0.131 \\
\hline PEU4 & 0.081 & 0.829 & -0.063 \\
\hline ANX1 & -0.094 & -0.047 & 0.407 \\
\hline ANX2 & -0.094 & -0.187 & 0.639 \\
\hline ANX3 & -0.086 & -0.114 & 0.873 \\
\hline ANX4 & -0.115 & -0.170 & 0.763 \\
\hline CSE1 & 0.503 & 0.319 & -0.164 \\
\hline CSE2 & 0.543 & 0.360 & -0.249 \\
\hline CSE3 & 0.651 & 0.196 & -0.169 \\
\hline CSE4 & 0.762 & 0.123 & -0.139 \\
\hline CSE5 & 0.855 & 0.055 & -0.093 \\
\hline CSE6 & 0.859 & 0.005 & -0.062 \\
\hline CSE7 & 0.770 & 0.183 & -0.045 \\
\hline CSE8 & 0.714 & 0.173 & -0.036 \\
\hline CSE9 & 0.856 & -0.012 & -0.043 \\
\hline CSE10 & 0.786 & 0.129 & -0.036 \\
\hline
\end{tabular}

Table 3 shows that the three-factor solution is reasonable and the items display desirable convergent and discriminant validity except for ANX1 and ANX2 for factor 3 and CSE1, CSE2 and CSE3 for factor 1 . ANX2 is relatively close to the 0.7 criterion suggested by Pedersen and Nysveen (2003). ANX1 however, although loads much higher on factor 3 than on the other factors, 
still a value of 0.407 is not acceptable. This may be due to the word 'apprehensive' used in the item and which may have been difficult for respondent to understand what it may imply. As for factor 1, and similarly to ANX2, CSE3 is close to the 0.7 criterion and is considered acceptable. CSE1 and CSE2 have loading values significantly lower than the 0.7 criterion and show weak discrimination from factor 2 with loading values of 0.319 for CSE1 and 0.360 for CSE2. Looking closely at the items of CSE1 and CSE2 in terms of how they differ from the other items, in an attempt to provide some insight into their low factor loading, we find that the only difference is that these questions are stated in a negative sense where CSE1 is composed of 'if there was no....' and CSE2 is composed of 'if I had never...'. These type of statements, which are completely different from the other 8 , seem to be not clear enough for the respondents.

It may be practical at this point to exclude ANX1, CSE1 and CSE2 from the following SEM analysis, but it is not recommended. The proposed model in this follows confirmatory analysis where the items and constructs have been validated by other studies. In order to validate the items and constructs for the present context, then exploratory factor analysis should be done; and that is a different methodology altogether.

\section{Assessment of Mediation}

The proposed mediation hypotheses are often tested by using a statistical technique suggested by Baron and Kenny (1986). Mediation is considered to be established based on the following criteria: (1) a significant relationship exists between the independent variable and the dependent variable; (2) a significant relationship exists between the independent variable and the presumed mediator; and (3) in the presence of a significant relationship, the previous significant relationship between the independent variable and the dependent variable is no longer significant or the strength of the relationship is significantly decreased. However, a test can be conducted to calculate the indirect effect and test its statistical significance to ascertain whether self-efficacy mediates the relationship between the anxiety (ANX) and PEU.

H1 hypothesized that anxiety has a significant effect on PEU. As shown in Figure 3, the effect of ANX on PEU was significant $(\beta=-0.276, t=-7.732, p=0.0001)$, and therefore supporting the hypothesis.

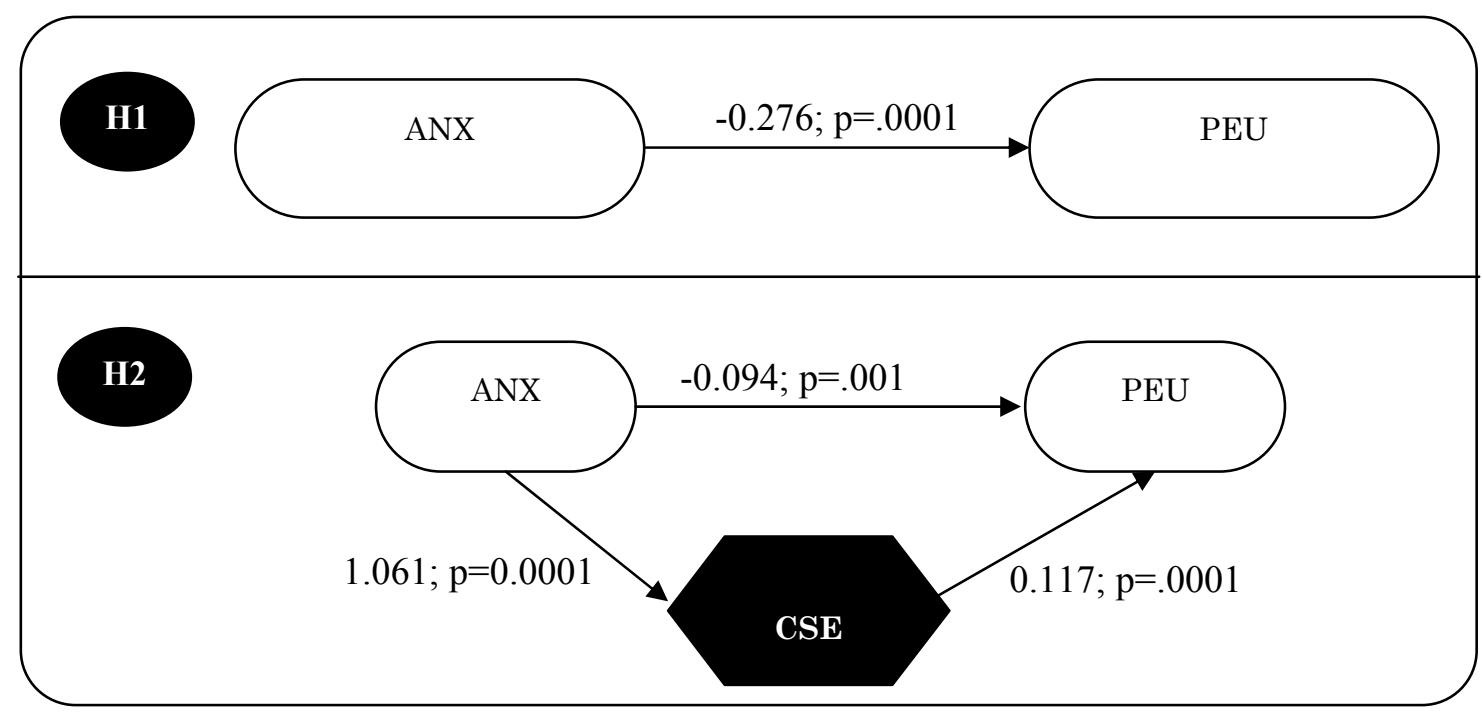

Figure 3. Mediation of anxiety 
$\mathrm{H} 2$ hypothesized that the effect of ANX on PEU would be mediated by computer self-efficacy (CSE). The relationship between ANX and CSE was significant $(\beta=1.061, p=0.0001)$. When PEU was regressed on both ANX and CSE, a significant relationship was found between CSE and PEU $(\beta=0.117, \mathrm{t}=-4.011, \mathrm{p}=0.0001)$ and the relationship between ANX and PEU was also significant $(\beta=-0.094, t=-3.466, p=0.001)$, thereby indicating that computer self-efficacy variable may have mediated the relationship between ANX and PEU since there is some decrease in the strength of the relationship between ANX and CSE $(\beta=-0.276, t=-7.732$ to $\beta=-0.094, t=-$ 3.466)

In addition, we tested (using the statistical software XLSTAT) to verify the mediating effect of the third variable CSE directly - the Sobel's or Goodman tests (Goodman, 1960; MacKinnon, Warsi, \& Dwyer, 1995; Sobel, 1982). These test yielded a $\mathrm{z}$-value $=342$ with $\mathrm{p}<0.000001$, thereby supporting H2 in that CSE does mediate the relationship between ANX and PEU (MacKinnon et al., 1995; Sobel, 1982). It is important to note that we were unable to determine the exact test used by the software: Sobel, Goodman (I), or Goodman (II) (Goodman, 1960; MacKinnon, Warsi, \& Dwyer, 1995; Sobel, 1982). However the statistical significance of the test was of such magnitude that we are confident that the z-value would reach significance for any of these tests.

\section{Discussion and Conclusions}

The primary objective of this study was to investigate the role that computer self-efficacy plays in mediating the impact of anxiety on perceived ease of use, in the context of the utilization of a learning management system. Computer self-efficacy was shown to indeed mediate the impact of ANX on PEU thereby supporting H2. Regression analysis demonstrated the significant role of mediation played by CSE. The analysis results seem to suggest that CSE does play an important role in mediating the ANX-PEU relationship for LMS usage.

In addition to the studies relating ANX with PEU, this study indicates that CSE can mediate this anxiety by reducing its effect on PEU. The situation is not as straightforward as it seems though. Our results support the existence of a strong and significant relationship between ANX and CSE and show that as student anxiety increases, the perception of ease of use of the LMS decreases or vice versa. Therefore, this may have implications on the idea that the quality of support, friendliness, and enthusiasm to the student using the LMS has a profound influence on the prevalence of computer anxiety (Rosen et al., 1995). This alone has major significant impact on how learning management systems should be designed and implemented.

Our study also shows that computer self-efficacy has a strong significant mediating influence on reducing the anxieties towards the LMS utilization. Implications to our findings suggest that prior to introducing prospective students to the LMS they should be tested for any computer anxieties they may have.

The findings demonstrate the contribution value of self-efficacy as a mediator to perceived ease of use of an LMS. With the continuous development of richer and more integrated interfaces, anxieties about learning to use the new interface and executing tasks effectively becomes of primary importance (Saadé \& Otrakji, 2007). As indicated in Smith, Caputi, Crittenden, Jayasuriya, and Rawstone (1999), as a means to better understand the dynamics of human computer interactions, qualitative feelings a person ascribes to some previous computer experience need to be understood. This construct might dominate as a predictor of successful and satisfied usage. Course designers and managers that desire to successfully implement LMSs in a higher education or training context need to be aware of this relationship in order to create an environment supportive of subjective attitude toward the artifact. 
Another key implication for designers/managers relates to guidelines for the design of LMSs. Positive learning using the LMS are more likely to be experienced with LMSs that are easy to use and introduce the least anxieties. Paying close attention to integrating simple, interactive, and familiar features in the design of LMSs and providing incentives to motivate its usage would assist those responsible for diffusion of the LMS via the mediating effect of computer self-efficacy.

\section{Limitations \& Suggestions for Future Research}

The results of this research must be considered in light of its limitations. We began with the questionnaire approach which is not free of subjectivity in the responses. The questionnaire was administered to a group of students coming from various cultural backgrounds (Asian, Middle Eastern, North American, and other) with a wide range of the English language skills. To that effect, although the items in the questionnaire were validated, this validation was done with a more homogeneous group in terms of English language proficiency. Moreover, while the respondents are undergraduate students and the subject matter is appropriate to them, caution must be taken in generalizing the results due to the fact that the mother tongue of the participants in this study varied significantly among four major backgrounds: English, French, Chinese, and Arabic.

Conclusions drawn in this study are based on the paradigm of e-learning and a specific LMS usage. The specificity of this study is that participants used learning tools that met specific learning and pedagogical objectives. The results, therefore, map into the specific learning tools used and a single distinct technology. As a result, caution should be taken when the results and findings are being generalized across other LMS technologies and learning tools/objects.

There are several potentially important implications. The findings demonstrate the value of addressing student anxieties as part of their e-learning experience in higher education. What was learned from this study includes the value of computer self efficacy to reduce students' computer anxiety aimed at enhancing their e-learning experience. Creating LMSs that are easy to use would increase the elements of success and enhance performance. However, it is worth noting that from a human-computer-interaction point of view, ease of navigation of an interface always comes at the cost of effective manipulation of tasks. In other words, the more 'easy to use' the interface is designed the less effective the features become, which reduces the capabilities of the LMS. To that effect, we introduce a ration between 'cognitive-cost' and 'effective-usage' that needs to be made optimized. With today's technologies, it is very feasible to realize a number of LMS interfaces built for students with different levels of computer self efficacy. This is where effective gains are measured.

From a practical perspective, companies are quite often engaged in training their employees. Companies find e-training attractive for many reasons but mainly because of the flexibility of time and space and its implications to cost savings. Companies spend money to train its employees in an attempt to increase the company's knowledge base and/or intelligence. The return on their investment placed on sponsoring their employees for continued education can be attained only if computer anxieties are mitigated. The present work may provide a better understanding about the effects of computer anxiety on learning and potentially help companies maximize the return on their 'e-training' investment by reducing those anxieties and increasing learning. From the LMS industry perspective, knowledge about the interplay between computer anxiety, computer self efficacy, and perceived ease of use of the LMS is of interest to practitioners who build different LMSs. Certainly, firms could use the results to enhance their understanding of what makes individuals perform better while using the LMSs.

Finally, from an assessment point of view, in this study we used four items to measure computer anxieties in general. Even with those, only two items, ANX3 and ANX4 loaded on the anxiety construct. Recall that there are three types of anxieties: trait, state, and concept-specific. We be- 
lieve that it is important to adapt the anxiety construct into these three sub-dimensions and investigate their influence of individual's e-learning experience. This would surely provide interesting results.

\section{References}

Adams, D. A., Nelson, R. R., \& Todd, A. P. (1992). Perceived usefulness, ease of use, and usage of information technology: a replication. MIS Quarterly 16(2), 227-247.

Ajzen, I., \& Fishbein, M. (1980). Understanding attitudes and predicting social behavior. Englewood Cliffs, NJ: Prentice-Hall.

Agarwal, R., \& Karahanna, E. (2000). Time flies when you're having fun: Cognitive absorption and beliefs about information technology usage. MIS Quarterly 24(4), 665-694.

Ayersman, D. J., \& Reed, W. M. (1995). Effects of learning styles, programming, and gender on computer anxiety. Journal of Research on Computing in Education, 28(2), 148-161.

Bandura, A. (1977). Self-efficacy: Toward a unifying theory of behavioral change. Psychological Review, 84(2), 191-215.

Bandura, A. (1978). Reflections on self-efficacy. Advances in Behavioral Research and Therapy, 1(4), 237269.

Bandura A. (1982) Self-efficacy mechanism in human agency. Journal of American Psychology, 37, 122147.

Bandura A. (1986a) The explanatory and predictive scope of self-efficacy theory, Journal of Society and Clinical Psychology, 4, 359-373.

Bandura, A. (1986b). Social foundations of thought and action. Englewood Cliffs, New Jersey: PrenticeHall.

Bandura, A. (1988). Reflection on nonability determinants of competence. In R. J. Sternberg \& J. Kolligian, Jr. (Eds.), Competence considered: Perceptions of competence and incompetence across the lifespan (pp. 315-362). Dordrecht, Netherlands: Kluwer Academic Publishers

Bandura, A., \& Cervone, D. (1986). Differential engagement of self-reactive mechanisms governing the motivational effects of goal systems. Organizational Behavior and Human Decision Processes, 38(1), 92-113.

Baron, M. R., \& Kenny, D. (1986). The moderator-mediator variable distinction in social psychological research: Conceptual, strategic, and statistical considerations. Journal of Personality and Social Psychology, 51(6), 1173-1182.

Brosnan, M. J. (1998a). The impact of computer anxiety and self-efficacy upon performance. Journal of Computer Assisted Learning, 14, 223-234.

Brosnan, M. J. (1998b). Technophobia: The psychological impact of information technology. New York: Routledge.

Brosnan, M. J. (1999). Modeling technophobia: A case for word processing. Computers in Human Behavior, $15(2)$ 105-121.

Chau, P. Y. K. (1996). An empirical assessment of a modified technology acceptance model. Journal of Management Information Systems, 13(2) 185-204.

Chau, S. L., Chen, D. T., \& Wong, L. F. A. (1999). Computer anxiety and its correlates: A meta-analysis. Computers in Human Behavior, 15, 609-623.

Compeau, D. R., Higgins, C. A., \& Huff, S. (1999). Social cognitive theory and individual reactions to computing technology: A longitudinal study. MIS Quarterly, 23(2), 145-158. 
Davis, F. D. (1986). A technology acceptance model for empirically testing new end-user information systems: theory and results. Doctoral Dissertation, Sloan School of Management, Massachusetts Institute of Technology.

Davis, F. D. (1989). Perceived usefulness, perceived ease of use, and user acceptance of information technology. MIS Quarterly, 13(3), 319-339.

Davis, F. D., Bagozzi, R. P., \& Warshaw, R. P. (1989). User acceptance of computer technology: A comparison of two theoretical models. Management Science, 35(8), 982-1003.

Deci, E. L., \& Ryan, R. M. (1985). Intrinsic motivation and self-determination in human behavior. New York: Plenum.

Gefen, D., Karahanna, E. \& Straub, D. W. (2003a). Inexperience and experience with online stores: The importance of TAM and trust. IEEE Transactions on Engineering Management, 50(3), 1-15.

Gefen, D., Karahanna, E. \& Straub, D. W. (2003b). Trust and TAM in online shopping: An integrated model. MIS Quarterly, 27(1), 51-90.

Gefen, D., \& Straub, D. W. (1997). Gender difference in the perception and use of e-mail: An extension to the technology acceptance model. MIS Quarterly, 21(4), 389-400.

Goodman, L. A. (1960). On the exact variance of products. Journal of the American Statistical Association, $55,708-713$.

Howard, G. S., \& Mendelow, A. L. (1991). Discretionary use of computers: An empirically derived explanatory model. Decision Sciences, 22, 241-265.

Howard, G. S., \& Smith, D. R. (1986). Computer anxiety in management: Myth or reality? Communications of the $A C M, 29(7), 611-615$.

Igbaria, M. (1993). User acceptance of microcomputer technology: An empirical test. OMEGA International Journal of Management Science. 21(1) 73-90.

Igbaria, M., \& Chakrabarti, A. (1990). Computer anxiety and attitudes towards microcomputer use. Behaviour and Information Technology, 9(3), 229-241.

Igbaria, M., \& Parasuraman, S. (1989). A path analytic study of individual characteristics, computer anxiety and attitudes toward microcomputers. Journal of Management, 15, 373-388.

Igbaria, M., Parasuraman, S., \& Baroudi, J. J. (1996). A motivational model of microcomputer usage. Journal of Management Information Systems, 13(1), 127-143.

Igbaria, M., \& Tan, M. (1997). The consequences of information technology acceptance on subsequent individual performance. Information and Management, 32(3), 113-121.

Ivari, J., \& Ervasti, I. (1994). User information satisfaction: IS implementability and effectiveness. Information and Management, 27(4), 205-220.

Lederer, A., Maupin, D., Sena, M. \& Zhuang, Y. (2000). The technology acceptance model and the world wide web. Decision Support Systems, 29(3), 269-282.

Leso, T. \& Peck, K. L. (1992). Computer anxiety and different types of computer courses. Journal of Educational Computing Research, 8(4), 469-478.

Lohmoller, J. B. (1989). Latent variable path modeling with partial least squares, Springer-Verlag, New York.

Lucas, H. C., \& Spitler, V. K. (1999). Technology use and performance: A field study of broker workstations. Decision Sciences, 30, 291-311.

MacKinnon, D. P., Warsi, G., \& Dwyer, J. H. (1995). A simulation study of mediated effect measures. Multivariate Behavioral Research, 30(1), 41-62.

McInerney, V., McInerney, D. M., \& Sinclair, K. E. (1994). Student teachers, computer anxiety, and computer experience. Journal of Educational Computing Research, 11(1), 27-50. 
Nunnally, J. C. (1978). Psychometric theory (2nd ed.). New York: McGraw-Hill.

Oetting, E. R. (1983). Oetting's computer anxiety scale (COMPAS). Ft. Collins, CO: Rocky Mountain Behavioral Science Institute.

Pedersen, P., \& Nysveen, H. (2003). Usefulness and self-expressiveness: Extending TAM to explain the adoption of a mobile parking services, In the Proceeding of $16^{\text {th }}$ Beld eCommerce Conference, Bled, Slovenia, June 9-11.

Reed, W. M., Ayersman, D. J., \& Liu, M. (1996). The effect of students' computer-based prior experiences and instructional exposures on the application of hypermedia-related mental models. Journal of Educational Computing Research, 14(2), 175-197.

Rosen, L. D. \& Weil, M. M. (1995). Computer anxiety: A cross-cultural comparison of university students in ten countries. Computers in Human Behavior, 11(1), 45-64.

Saadé, R. (2003). Web-based education information system for enhanced learning, EISEL: Student assessment. Journal of Information Technology Education, 2, 267-277. Retrieved from http://jite.org/documents/Vol2/v2p267-277-26.pdf

Saadé, R. (2007). Exploring dimensions to perceived usefulness: Towards an enhanced assessment. Decision Sciences Institute - Decision Sciences Journal of Innovative Education, 5(2).

Saadé, R., \& Bahli, B. (2005). The impact of cognitive absorption on perceived usefulness and perceived ease of use in on-line learning: An extension of the technology acceptance model. Information \& Management, 42(2), 317-327.

Saade, R., \& Kira, D. (2007). Mediating the impact of technology usage on perceived ease of use by anxiety. Computers \& Education, 49(4), 1189-1204.

Saadé, R., \& Otrakji, C. (2007), First impressions last a lifetime: Effect of disorientation and cognitive load. Computers in Human Behavior, 23(1), 525-535.

Schunk, D. H. (2000). Learning theories in educational perspectives. Prentice Hall.

Schlenker, B. R., \& Leary, M. R. (1982), Social anxiety and self-presentation: Conceptualization and model. Psychological Bulletin, 92(3), 641-669.

Smith, B., Caputi, P., Crittenden, N., Jayasuriya, R. \& Rawstone, P. (1999). A review of the construct of computer experience. Computers in Human Behaviour, 15, 227-242.

Sobel, M. E. (1982). Asymptotic intervals for indirect effects in structural equations models. In S. Leinhart (Ed.), Sociological methodology 1982 (pp.290-312). San Francisco: Jossey-Bass.

Spielberger, C. D. (1972). Anxiety: Current trends in theory and research (Vol. I). New York, N.Y.: Academic Press.

Venkatesh, V. \& Davis, F. D. (2000). A theoretical extension of the technology acceptance model: Four longitudinal field studies. Management Science, 46(2), 186-204.

Venkatesh, V. \& Morris, M. G. (2000). Why don't men ever stop to ask for directions? Gender, social influence, and their role in technology acceptance and usage behavior. MIS Quarterly, 24(1), 115-139. 


\section{Biographies}

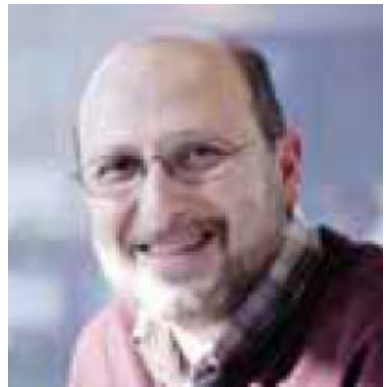

Dr. Raafat Saadé is a lecturer at the DSMIS department, John Molson School of Business, Concordia University, Canada. Dr. Saadé obtained his Ph.D. in 1995 from Concordia University. He subsequently received the Canadian National Research Council postdoctoral fellowship, which he completed at McGill University (Montreal). He has been recognized twice as a North Atlantic Treaty Organization ASI award winner. Dr. Saadé has 19 years of industrial experience (engineering, elearning, ehealth, cross-cutting themes - gender $\&$ sustainability - \& application of Information Communication Technologies, ICT, in international projects - Pakistan, Ukraine, Bahrain...). He is very active in research with over 30 peer refereed journal articles. Dr. Saadé has published in top tier journals including Information \& Management, Journal of Information Systems in Education, Expert Systems with Applications, Journal of Asynchronous Learning Networks and Decision Sciences.

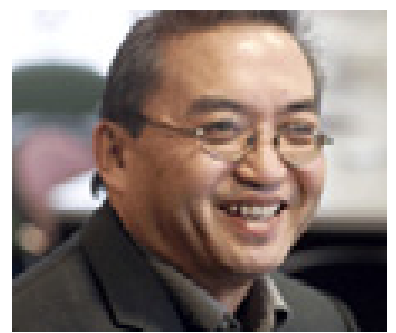

Dr. Dennis Kira is an associate professor at the Decision Sciences MIS department, John Molson School of Business, Concordia University, Canada. He has been with the Faculty since 1983. He obtained his Ph.D. from University of British Columbia. Dr. Kira teaches System design, decision support systems, data management, data mining, Internet related programming, and e-commerce His research activities include Ecommerce, web design, distance learning, decision making under uncertainty, neural networks, machine learning, and financial modeling. Dr. Kira has published in IEEE, ORQ and management science among other journals. 